\title{
Article \\ Reduced-Order Extended State Observer-Based Sliding Mode Control for All-Clamped Plate Using an Inertial Actuator
}

\author{
Juan Zhai ${ }^{1}$, Shengquan $\mathrm{Li}^{2}{ }^{2} * \mathbb{C}$, Zhuang $\mathrm{Xu}^{2}$, Luyao Zhang ${ }^{2}$ and Juan $\mathrm{Li}^{2}$ \\ 1 College of Guangling, Yangzhou University, Yangzhou 225000, China; 060081@yzu.edu.cn \\ 2 College of Electrical, Energy and Power Engineering, Yangzhou University, Yangzhou 225127, China; \\ xuzhuang1234@163.com (Z.X.); mx120200626@yzu.edu.cn (L.Z.); juanli@yzu.edu.cn (J.L.) \\ * Correspondence: sqli@yzu.edu.cn
}

Citation: Zhai, J.; Li, S.; Xu, Z.; Zhang, L.; Li, J. Reduced-Order Extended State Observer-Based Sliding Mode Control for All-Clamped Plate Using an Inertial Actuator. Energies 2022, 15, 1780. https://doi.org/10.3390/en15051780 Academic Editor: Yougang Sun and Gheorghe-Daniel Andreescu

Received: 30 January 2022

Accepted: 24 February 2022

Published: 28 February 2022

Publisher's Note: MDPI stays neutral with regard to jurisdictional claims in published maps and institutional affiliations.

Copyright: (C) 2022 by the authors. Licensee MDPI, Basel, Switzerland. This article is an open access article distributed under the terms and conditions of the Creative Commons Attribution (CC BY) license (https:// creativecommons.org/licenses/by/ $4.0 /)$.

\begin{abstract}
Considering the problems of total disturbances, i.e., higher harmonics, model uncertainties and external excitations in a practical vibration control system, a compound vibration suppression method is proposed for an all-clamped plate, which combines sliding mode control (SMC) with reduced-order extended state observer (RESO). First, a state space model of the all-clamped plate with inertial actuator is established. Second, a RESO is designed to estimate the system state variables and total disturbances in real time. In addition, the total disturbances can further be attenuated by RESO through a feedforward compensation part. Third, a sliding mode controller based on the estimation values is designed for a vibration control system. The Lyapunov stability theorem is further applied to prove the stability of the whole closed-loop vibration control system with the proposed controller. Finally, vibration control experiment equipment is built based on the NI-PCIe acquisition card, inertial actuator and acceleration sensor to verify the vibration suppression performances of the proposed method. The experimental results show that the amplitude value of vibration has been reduced by $75.2 \%$ with the proposed method, while the amplitude value is reduced by $54.5 \%$ with the traditional sliding mode control method based on an extended state observer (SMC-ESO). The comparative experimental results illustrate that the proposed method has excellent anti-disturbance and vibration suppression performances.
\end{abstract}

Keywords: sliding mode control; all-clamped plate; reduced-order extended state observer; vibration suppression

\section{Introduction}

Thin plate materials are widely applied in engineering fields, including aerospace engineering, ships and warships, vehicle engineering and mechanical engineering, due to their light weight and large flexibility [1,2]. However, it is very easy to be excited by model uncertainties, higher harmonics and unknown external excitations, resulting in resonance and noise, structural damage, safety reduction and system collapse. In addition, there are other factors causing vibration, such as shell vibration caused by marine propulsion shafting, coupling vibrations between traction motor and driveline and the panel fluttering caused by air flow in a narrow passage [3-5]. Therefore, vibration suppression has great research significance in engineering fields [6,7]. In recent years, inertial actuators have been widely pasted on the all-clamped plate as actuators of vibration suppression control, because inertial actuators can precisely suppress vibration in a broad band with rigorous structural requirements [8,9].

Various advanced methods have already been studied to suppress the vibration of an all-clamped plate effectively. Direct velocity feedback control is applied in practice by using band-pass filter to integrate the signal of the acceleration sensor $[10,11]$. Proportional control, integral control, derivative control and PID methods are applied in Ref. [12], respectively, to reduce the vibration and sound radiation of a flat panel. Phase compensation 
is adopted to deal with the phase displacement problem caused by inertial actuators [13]. An optimal velocity feedback controller is proposed to use the least kinetic energy and consume the most energy [14]. Although these vibration control methods have the advantages of uncomplicated structure and easy application, the performance is very dependent on accurate mathematical models of the system. However, modeling errors inevitably exist in the actual vibration experiment because of the uncertainty of model parameters, complex boundary conditions, measurement noise, unknown external forces and high order harmonics [15]. Therefore, controllers relying on models are difficult for obtaining satisfactory control results with total disturbances [16-18]. In the last few decades, many active vibration control methods have been proposed to address the challenges of total disturbances and nonlinearity $[19,20]$. These control methods can improve the anti-disturbance ability in different aspects, but it is difficult to suppress the total disturbances effectively without an accurate mathematical model. For instance, the superiority of the sliding mode control method is that it has a strong anti-disturbance ability [21], while the use of the SMC method is constrained due to the sensitivity of mismatched disturbance and the chattering phenomenon [22]. In order to deal with the difficulty, the disturbance estimation methods are proposed to eliminate the disturbances and uncertainties of the system, which can solve the chattering phenomenon completely. The disturbance-observer-based controller (DOBC) has been broadly applied in industrial control systems via a feedforward part to compensate internal and external disturbances [23]. Following the direction, the SMC method based on a nonlinear disturbance observer (NDOB) has been proposed to eliminate the mismatched disturbance [24]. The disturbance observer combined with an integral sliding mode control (ISMC) can effectively counteract serious chattering for the system with mismatched disturbance by introducing a low pass filter [25].

Extended state observer (ESO) is another disturbance estimation method for the total disturbances, originally proposed by Han [26]. The control framework based on ESO, i.e., active disturbance rejection control (ADRC), can also compensate the total disturbances via the feedforward part to improve system performance $[27,28]$. Recently, ADRC has excellent control characteristics in handling uncertain objects and decoupling control, so it has been widely applied in industrial systems. In addition, chattering phenomenon generated by SMC can be defined as total disturbance and compensated through ESO [29]. The satisfactory anti-disturbance performance can be obtained by selecting a large value observer bandwidth of ESO, while the increasing observer gain of the bandwidth will bring the poor anti-noise ability [30]. In Ref. [31], a RESO is applied to address the problem of poor anti-noise ability caused by the increase of bandwidth gain, and it is easier to implement than ESO.

Considering the chattering and the increasing of the bandwidth value, a sliding mode control method based on a reduced-order extended state observer is proposed to achieve the excellent control performance of the all-clamped panel vibration suppression system for reducing noise in this paper. In particular, the proposed method can obviously reduce chattering. In addition, a RESO is designed to obtain a lower bandwidth gain, aiming at addressing the problem of poor anti-noise ability caused by the increase of bandwidth gain.

The main content of this paper is as follows. A practical mathematic model of the all-clamped plate vibration system with the inertial actuator is given in Section 2. A sliding mode controller based on a reduced-order extended state observer (RESO) is designed in Section 3, to suppress the structural vibration. Then, the stability of the proposed vibration suppression method is discussed in detail in Section 4 . The experimental results on vibration control are given to compare the proposed sliding mode control method based on reduced-order extended state observer (SMC-RESO) against the traditional SMC-ESO in Section 5. Finally, a summary of the whole paper is provided in Section 6. 


\section{System Description}

\subsection{Mathematic Model of the All-Clamped Plate}

The typical model description of the all-clamped plate with an inertial actuator studied is shown in Figure 1. The inertial actuator $m_{s}$ is connected to the structure mass $m$ via stiffness coefficient $k_{s}$ and damping coefficient $c_{s}$. The parameter $m$ is connected to the ground through stiffness coefficient $k$ and damping coefficient $c$. An inductor $L_{e}$ and a resistor $R_{e}$ are connected in series to form the electrical impedance of the inertial actuator. The voltage across the coil is expressed as $u_{e}$. The vibration output $x_{s}$ and $x$ represent the displacement of $m_{s}$ and $m$, respectively. The force $F$ is produced by external disturbance, while the force $f$ is caused by supplying alternating current $i$ to the coil. Due to the structure drawing of the system in Figure 1, the related equations of the system can be established as follows:

$$
\begin{gathered}
m_{s} \ddot{x}_{s}+c_{s}\left(\dot{x}_{s}-\dot{x}\right)+k_{s}\left(x_{s}-x\right)=-B l i, \\
L_{e} \frac{d i}{d t}+R_{e} i+B l\left(\dot{x}_{s}-\dot{x}\right)=u, \\
m \ddot{x}+c \dot{x}+k x+c_{s}\left(\dot{x}-\dot{x}_{s}\right)+k_{s}\left(x-x_{s}\right)=B i l+F,
\end{gathered}
$$

where $B$ and $l$ are electromagnetic inductance coefficient and coil length, respectively.

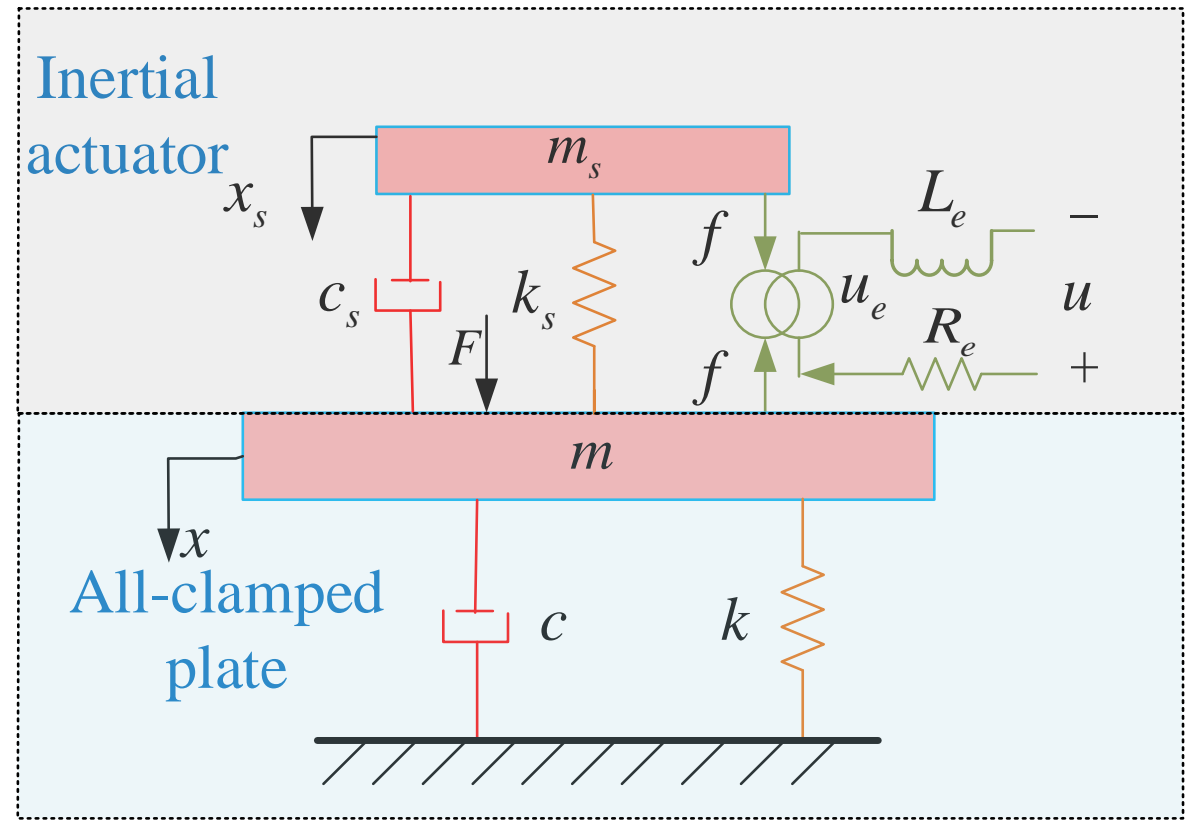

Figure 1. Structure drawing of all-clamped plate with inertial actuator.

According to the Equations (1)-(3), the system variables can be defined as $x_{1}=x, x_{2}=\dot{x}, x_{3}=x_{s}, x_{4}=\dot{x}_{s}, x_{5}=i, d=\frac{F}{m}$, so the system state space model can be simplified as follows:

$$
\left[\begin{array}{l}
\dot{x}_{1} \\
\dot{x}_{2} \\
\dot{x}_{3} \\
\dot{x}_{4} \\
\dot{x}_{5}
\end{array}\right]=\left[\begin{array}{ccccc}
0 & 1 & 0 & 0 & 0 \\
\frac{-k_{s}-k}{m} & \frac{-c_{s}-c}{m} & \frac{k_{s}}{m} & \frac{c_{s}}{m} & \frac{B l}{m} \\
0 & 0 & 0 & 1 & 0 \\
\frac{k_{s}}{m_{s}} & \frac{c_{s}}{m_{s}} & -\frac{k_{s}}{m_{s}} & -\frac{c_{s}}{m_{s}} & -\frac{B l}{m_{s}} \\
0 & \frac{B l}{L_{e}} & 0 & -\frac{B l}{L_{e}} & -\frac{R_{e}}{L_{e}}
\end{array}\right]\left[\begin{array}{c}
x_{1} \\
x_{2} \\
x_{3} \\
x_{4} \\
x_{5}
\end{array}\right]+\left[\begin{array}{cc}
0 & 0 \\
0 & 1 \\
0 & 0 \\
0 & 0 \\
\frac{1}{L_{e}} & 0
\end{array}\right]\left[\begin{array}{l}
u \\
d
\end{array}\right]
$$

Due to the displacement and velocity of the all-clamped plate being seriously coupled with the displacement and velocity of the inertial actuator, two sensors are needed to 
measure the motion physical quantities of the all-clamped plate and the inertial actuator, respectively, which will increase the cost. The vibration output parameters $x_{3}$ and $x_{4}$ of the inertial actuator can be regarded as disturbance to the all-clamped plate, so the system model is improved as follows by taking the Laplace transform of $\dot{x}_{5}=f\left(x_{2}, x_{4}, x_{5}\right)+\frac{u}{L_{e}}$ in Equation (4):

$$
\begin{gathered}
x_{5}(s)=\frac{\frac{R_{e}}{L_{e}}}{s+\frac{R_{e}}{L_{E}}}\left(\frac{B l}{R_{e}} x_{2}(s)-\frac{B l}{R_{e}} x_{4}(s)+\frac{1}{R_{e}} u(s)\right) \\
=G(s)\left(\frac{B l}{R_{e}} x_{2}(s)-\frac{B l}{R_{e}} x_{4}(s)+\frac{1}{R_{e}} u(s)\right)
\end{gathered}
$$

\subsection{Problem Statement}

The Bode diagram of $G(s)$ has been drawn as shown in Figure 2 with $L_{e}=0.002 \mathrm{mH}$ and $R_{e}=7.5 \Omega$ can be measured. According to Figure 2, the value of $G(s)$ can be regarded as equal to 1, when the frequency is less than $1000 \mathrm{rad} / \mathrm{s}$. So, Equation (5) can be further deduced as follows:

$$
x_{5} \approx\left(\frac{B l}{R_{e}} x_{2}-\frac{B l}{R_{e}} x_{4}+\frac{1}{R_{e}} u\right)
$$

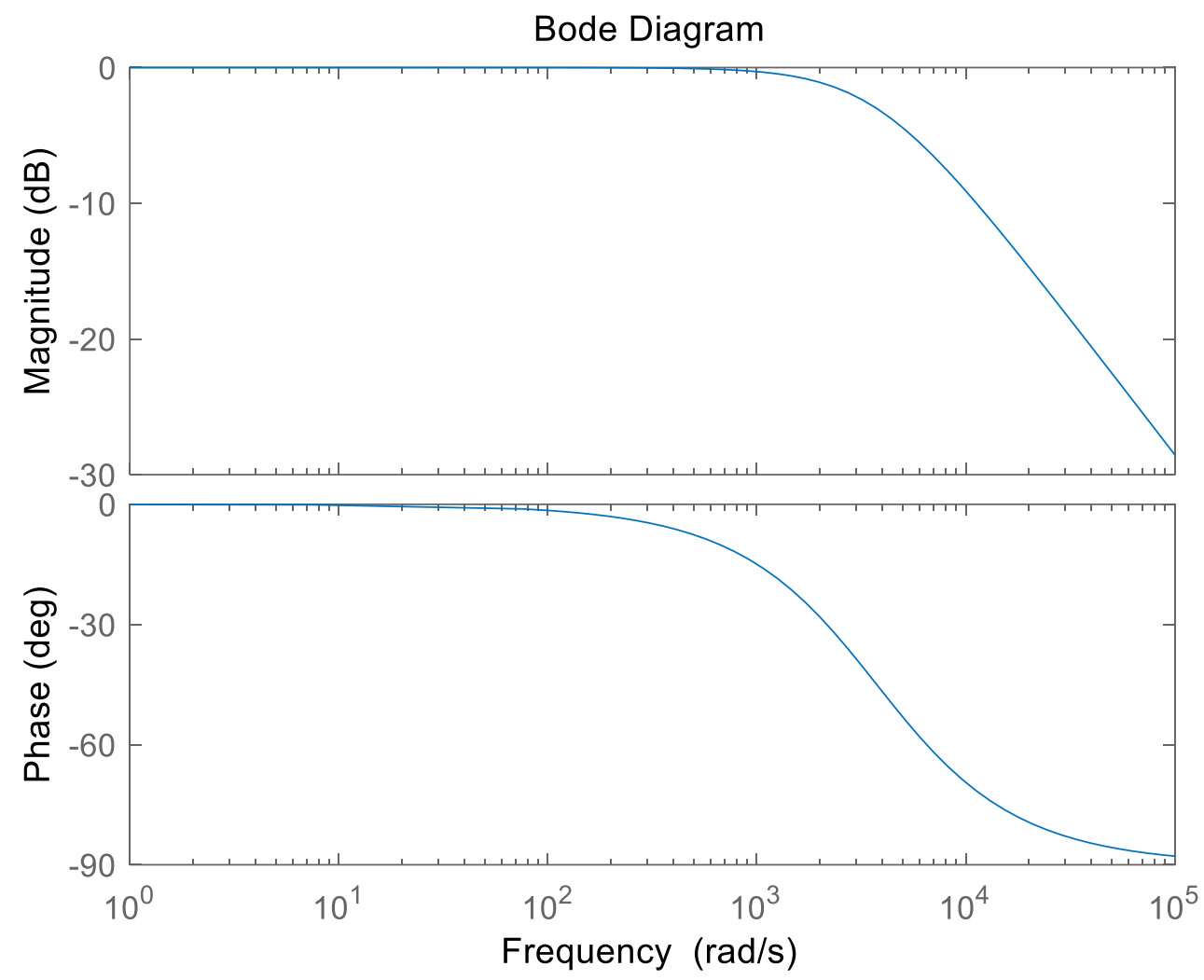

Figure 2. Bode diagram of transfer function $\mathrm{G}(\mathrm{s})$.

According to Equation (6), Equation (4) can be re-written as a second order equation as follows:

$$
\left[\begin{array}{c}
\dot{x}_{1} \\
\dot{x}_{2}
\end{array}\right]=\left[\begin{array}{cc}
0 & 1 \\
-\frac{k_{s}+k}{m} & -\frac{R_{e}\left(c_{s}+c\right)-(B l)^{2}}{m R_{e}}
\end{array}\right]\left[\begin{array}{l}
x_{1} \\
x_{2}
\end{array}\right]+\left[\begin{array}{cc}
0 & 0 \\
\frac{k_{s}}{m} & \frac{c_{s} R_{e}-(B l)^{2}}{m R_{e}}
\end{array}\right]\left[\begin{array}{c}
x_{3} \\
x_{4}
\end{array}\right]+\left[\begin{array}{c}
0 \\
\frac{B l}{m R_{e}}
\end{array}\right] u+\left[\begin{array}{l}
0 \\
1
\end{array}\right] d
$$


where $A_{1}=\left[\begin{array}{cc}0 & 1 \\ -\frac{k_{s}+k}{m} & -\frac{R_{e}\left(c_{s}+c\right)-(B l)^{2}}{m R_{e}}\end{array}\right], A_{2}=\left[\begin{array}{cc}0 & 0 \\ \frac{k_{s}}{m} & \frac{c_{s} R_{e}-(B l)^{2}}{m R_{e}}\end{array}\right], B=\left[\begin{array}{ll}0 & \frac{B l}{m L_{e}}\end{array}\right]^{T}$, $E=\left[\begin{array}{ll}0 & 1\end{array}\right]^{T}, \zeta=\left[\begin{array}{ll}x_{1} & x_{2}\end{array}\right]^{T}, \mu=\left[\begin{array}{ll}x_{3} & x_{4}\end{array}\right]^{T}$, so Equation (7) can be abbreviated as follows:

$$
\dot{\zeta}=A_{1} \zeta+A_{2} \mu+B u+E d
$$

Remark 1. The polynomial $A_{1} \zeta$ and $A_{2} \mu$ are the model data of the all-clamped plate system, which can be classified as the internal disturbance and the external disturbances generated by the model error and inertial actuator effects on the system, respectively. The parameterEd is regarded as external disturbance from external incentives. The coefficient $B$ is the gain matrix of the controller. So, the vibration control system can be described as the following state-space model.

$$
\left\{\begin{array}{l}
\dot{x}_{1}=x_{2} \\
\dot{x}_{2}=f_{d}+b_{0} u \\
y=x_{1}
\end{array}\right.
$$

This article highlights two main issues. (1) The above internal and external disturbance are defined as total disturbances $f_{d}$. (2) A RESO is designed to obtain a lower bandwidth gain, aiming at addressing the problem of poor anti-noise ability caused by the increase of bandwidth gain. In addition, the calculation of the controller becomes much simpler with RESO.

\section{Controller Design for the Structural Vibration System}

\subsection{Traditional Extended State Observer Design}

The target displacement of the system is $r=0$, so the state space model of system can be written as following state space model with tracking error $e_{1}=r-x_{1}$.

$$
\left\{\begin{array}{l}
\dot{e}_{1}=e_{2} \\
\dot{e}_{2}=-f_{d}-b_{0} u
\end{array},\right.
$$

where $b_{0}$ is the estimation value of $b$. Due to the error between real and estimated total disturbances, Equation (10) can also be further described as Equation (11) with $v=u+\hat{f}_{d} / b_{0}$ and $\varepsilon=\hat{f}_{d}-f_{d}$.

$$
\left\{\begin{array}{l}
\dot{e}_{1}=e_{2} \\
\dot{e}_{2}=e_{3}-b_{0} v \\
\dot{e}_{3}=\dot{\varepsilon}
\end{array}\right.
$$

where $\hat{f}_{d}$ is the estimated value of the total disturbances. The parameter $\varepsilon$, described by a new disturbance variable attenuated by sliding mode controller, is the error between $f_{d}$ and $\hat{f}_{d}$. If it is precisely estimated, the total disturbances will be attenuated to be zero. According to Equation (11), the ESO can be designed as follows:

$$
\left\{\begin{array}{l}
e=\lambda_{1}-e_{1} \\
\dot{\lambda}_{1}=\dot{\lambda}_{2}-\beta_{1} e \\
\dot{\lambda}_{2}=\dot{\lambda}_{3}-\beta_{2} e-b_{0} u \\
\dot{\lambda}_{3}=-\beta_{3} e
\end{array},\right.
$$

where $\lambda_{i}(i=1,2,3)$ are the estimated value of $e_{i}$, and $\beta_{i}$ are the gains of ESO. The value can be obtained according to the bandwidth method in Ref. [32].

\subsection{Reduced-Order Extended State Observer Design}

If the bandwidth value of the observer is larger, the gain of the high frequency band becomes larger, while the anti-noise capability of the system becomes worse. In addition, a 
second-order RESO is designed because the value of system state $e_{1}$ can be measured by sensors. According to Equation (11), the RESO is established as follows:

$$
\left\{\begin{array}{l}
\dot{z}_{2}=z_{3}+\beta_{02} e_{1}-\beta_{01}\left(z_{2}+\beta_{01} e_{1}\right)-b_{0} u \\
\dot{z}_{3}=-\beta_{02}\left(z_{2}+\beta_{01} e_{1}\right) \\
\hat{e_{2}}=z_{2}+\beta_{01} e_{1} \\
\hat{e_{3}}=z_{3}+\beta_{02} e_{1}
\end{array},\right.
$$

where $\beta_{01}, \beta_{02}$ are defined as the gains of RESO. The parameters $z_{2}, z_{3}$ are state variables of RESO. $\hat{e_{2}}, \hat{e_{3}}$, which represent the estimated value of $e_{2}, e_{3}$, are the outputs of RESO. According to the bandwidth method, the RESO gains can be given as $\beta_{01}=2 \omega_{0}, \beta_{02}=\omega_{0}{ }^{2}$, so the estimated speed value of RESO can be accelerated if there is no need to estimate $e_{1}$.

\subsection{Sliding Mode Controller Design}

Considering the state space error model, there exists three characteristics. First, external disturbances and internal uncertainties are defined as total disturbances without considering the type of disturbance. Second, a chattering phenomenon generated by SMC can be defined as total disturbances and compensated through RESO. In addition, the observer error in Equation (11) is smaller than that in Equation (10), which is attenuated by $\mathrm{SMC}$, so the sliding surface is designed as follows:

$$
s=c e_{1}+\dot{e}_{1}
$$

where $c$ is a positive value of the sliding mode surface, which satisfies Hurwitz's condition, so the derivative of the sliding mode surface could be obtained as follows:

$$
\dot{s}=c \dot{e}_{1}+\ddot{e}_{1}=c e_{2}+\varepsilon-b_{0} v
$$

Exponent reaching law Equation (16) is selected as follows:

$$
\dot{s}=-k s-\eta \text { sgns, }
$$

where $k$ is the speed that system reaches at the sliding surface. The symbols sgns and $\eta$ are the sign function and the parameter of sign function, respectively. When $s$ is larger, which means moving point far from sliding mode surface, the system can reach at the sliding surface fast. When $s$ is small, the system can reach at the sliding mode surface in limited time by sign function. According to Equations (15) and (16), the control law is expressed as follows:

$$
v=1 / b_{0}\left(c e_{2}+k s+\varepsilon+\eta \operatorname{sgn} s\right)=1 / b_{0}\left(c e_{2}+k s+\eta^{\prime} \text { sgns }\right),
$$

where the value of $\eta^{\prime}$ satisfies $\eta^{\prime} \geq|\varepsilon|+|\eta|$. The magnitude of chattering is related to the value of $\eta^{\prime}$. Chattering can be eliminated when disturbances are attenuated to zero with accurate estimation of total disturbances by RESO. Finally, the control law of SMC-RESO is derived as follows:

$$
u=1 / b_{0}\left(c \hat{e}_{2}+k s+\eta^{\prime} \operatorname{sgn} s-\hat{e}_{3}\right)
$$

The SMC-RESO control system for all-clamped plate is shown in Figure 3. The estimation value of total disturbances is eliminated in the feedforward part; thus, the burden of the sliding mode controller can be reduced. 


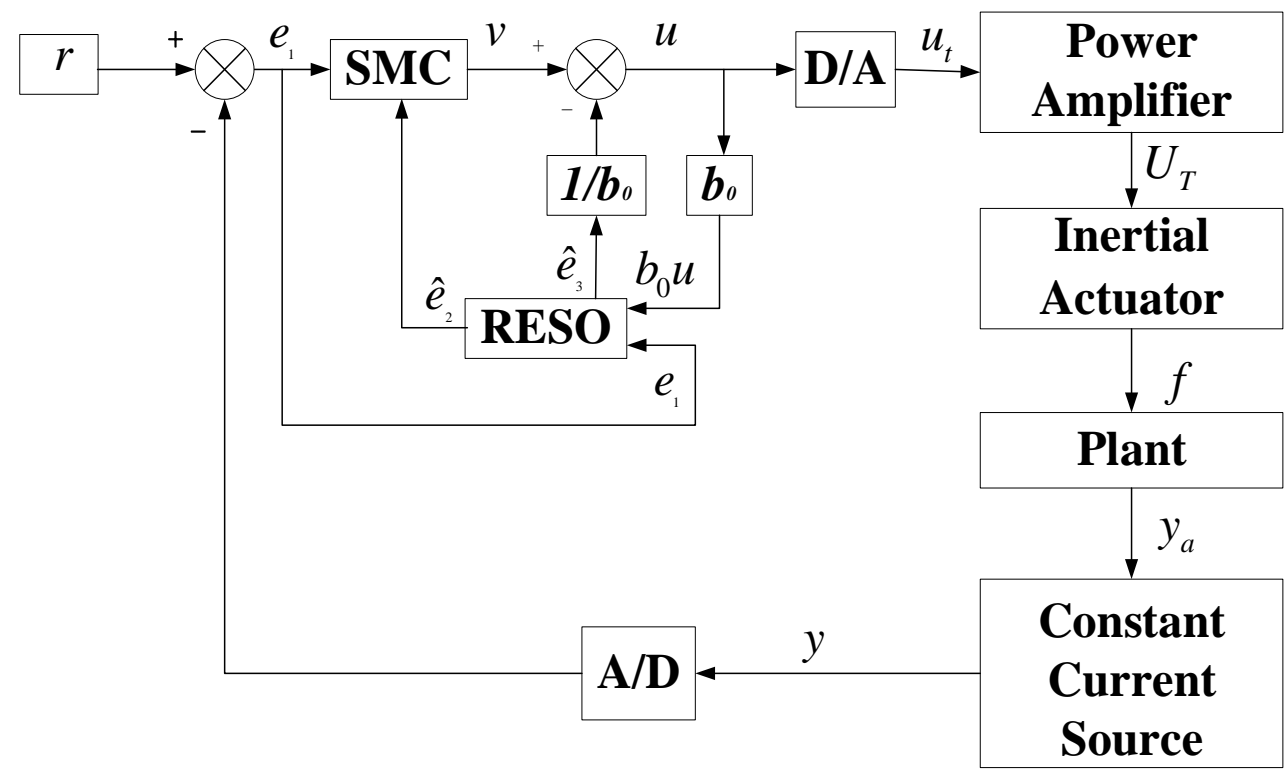

Figure 3. Vibration control system structure.

\section{Stability Analysis of the Proposed Controllers}

\subsection{Convergence Analysis of RESO}

The observed error of RESO is defined as $E_{2}=\hat{e}_{2}-e_{2}, E_{3}=\hat{e}_{3}-e_{3}$, and then Equation (19) can be obtained as the follows:

$$
\left\{\begin{array}{l}
\dot{E}_{2}=-\beta_{01} E_{2}+E_{3} \\
\dot{E}_{3}=-\beta_{02} E_{2}-\dot{\varepsilon}
\end{array}\right.
$$

Equation (19) can be further written into the state space form as follows:

$$
\left[\begin{array}{c}
\dot{E}_{2} \\
\dot{E}_{3}
\end{array}\right]=\left[\begin{array}{ll}
-\beta_{01} & 1 \\
-\beta_{02} & 0
\end{array}\right]\left[\begin{array}{c}
E_{2} \\
E_{3}
\end{array}\right]+\left[\begin{array}{c}
0 \\
-\dot{\varepsilon}
\end{array}\right]
$$

Then, the characteristic polynomial of Equation (20) can be obtained:

$$
\operatorname{det}(\rho I-A)=\rho^{2}+\beta_{01} \rho+\beta_{02}=\left(\rho+\omega_{0}\right)^{2},
$$

where $\rho=-\omega_{0}<0$, and $\dot{\varepsilon}$ is bounded. In addition, the poles of the system are located in the left half plane, so the proposed RESO is convergent.

\subsection{Stability Analysis of Sliding Mode Controller}

The vibration system is composed of the abovementioned. The stability of the sliding mode controller can be proved by the Lyapunov stability criterion by selecting the following Lyapunov function:

$$
V=\frac{1}{2} s^{2}
$$

The derivative of Equation (22) is obtained as follows:

$$
\begin{aligned}
& \dot{V}=s \dot{s}=s\left(c z_{2}-b_{0} v+\varepsilon\right)=s\left(-k s-\eta^{\prime} \text { sgn } s+\varepsilon\right) \leq \\
& s\left(-k s-\eta^{*} \text { sgns }\right)=-k|s|^{2}-\eta^{*}|s|<0
\end{aligned}
$$

where the value of $\eta^{*}$ satisfies $\eta^{*}>\left|\eta^{\prime}\right|+|\varepsilon| \geq 0$. The designed sliding mode controller satisfies Lyapunov stability criterion. Therefore, the system can move to the 
sliding mode surface $s=0$ in limited time. The sliding mode motion can be described as follows:

$$
s=c e_{1}+\hat{e}_{2}=0,
$$

Equations (25) and (26) can be derived from Equation (24):

$$
\begin{gathered}
s=c e_{1}+\hat{e}_{2}+\dot{e}_{1}-\dot{e}_{1}=c e_{1}+\dot{e}_{1}+E_{2}=0, \\
\dot{e}_{1}=-c e_{1}-E_{2}=0
\end{gathered}
$$

Combining Equations (20) and (26), the system state space model can be described as follows:

$$
\begin{aligned}
{\left[\begin{array}{c}
\dot{e}_{1} \\
\dot{E}_{2} \\
\dot{E}_{3}
\end{array}\right] } & =\left[\begin{array}{ccc}
-c & -1 & 0 \\
0 & -\beta_{01} & 1 \\
0 & -\beta_{02} & 0
\end{array}\right]\left[\begin{array}{c}
e_{1} \\
E_{2} \\
E_{3}
\end{array}\right]+\left[\begin{array}{c}
0 \\
0 \\
-\dot{\varepsilon}
\end{array}\right], \\
\operatorname{det}(\rho I-A) & =\rho^{3}+\left(\beta_{01}+c\right) \rho^{2}+\left(\beta_{01} c+\beta_{02}\right) \rho+\beta_{02} c=0,
\end{aligned}
$$

where the parameter $\dot{\varepsilon}$ is bounded. By choosing suitable parameters, the poles of the characteristic polynomial are arranged in the left half plane to make the system stable. Then, the state of the closed loop system converges asymptotically to the origin value along the sliding mode surface.

\section{Experimental Verification}

\subsection{Experimental Set-Up}

An all-clamped plate with dimensions $500 \mathrm{~mm} \times 500 \mathrm{~mm} \times 1 \mathrm{~mm}$ is researched to verify the effectiveness of the SMC-RESO method studied in this paper. The vibration control platform built is shown in Figure 4. The PSV-500 laser vibrator measures inherent vibration mode of the all-clamped plate. The inertial actuator and acceleration sensor (IEPE CA-YD-160) are pasted at the place of maximum strain with the principle of collocated configuration. The HEV-20 exciter is placed on the right side of the panel to simulate the external disturbance excitation, and select a sinusoidal excitation signal with a first-order mode frequency of $48.5 \mathrm{~Hz}$. The input signal collected by NI PCI-6343 is amplified through the constant-current source adaptor and transmitted to the Analog Input port in Simulink (MATLAB). Then, the control signal processed by controller is transmitted to the Analog Output port, which will be amplified by a power amplifier (HVP-300) to make the inertial actuator control the vibration of the all-clamped plate. The parameters of the inertial actuator used in the experiment are shown in Table 1.

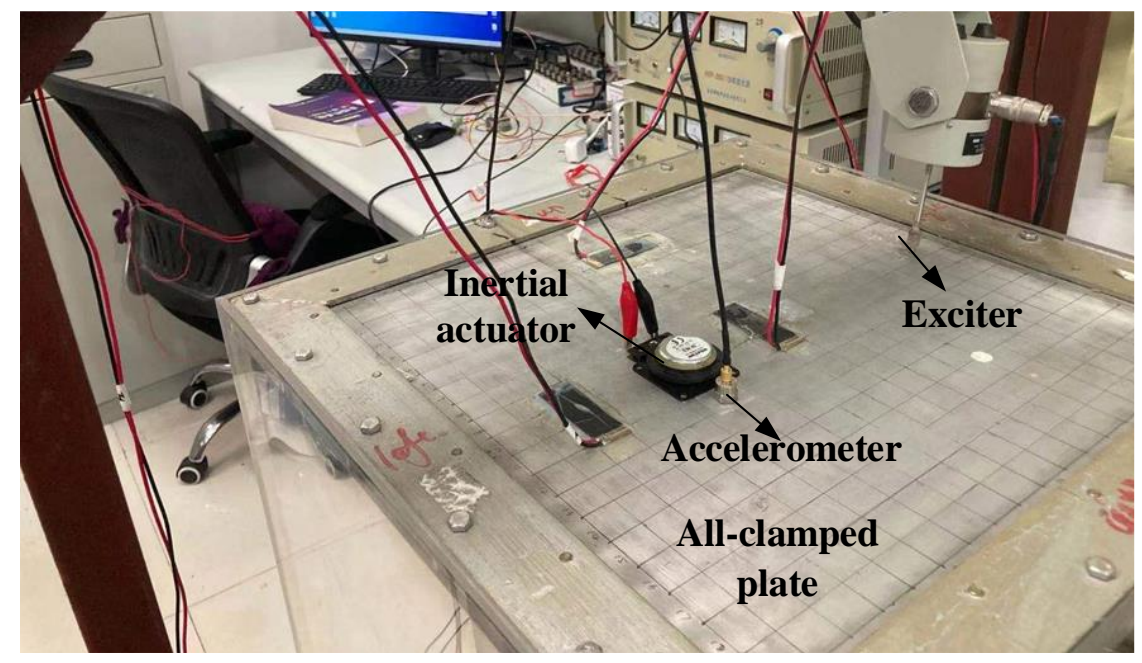

Figure 4. The experimental platform of vibration control. 
Table 1. Inertial actuator parameter.

\begin{tabular}{cc}
\hline Parameter & Value \\
\hline Quality, $m_{a}(\mathrm{~kg})$ & 0.06 \\
Stiffness, $r_{a}(\mathrm{~N} / \mathrm{m})$ & 710.61 \\
Damping ratio, $k_{a}$ & 0.02 \\
Force constant, $B L(\mathrm{~N} / \mathrm{A})$ & 3.4 \\
Coil resistance, $R_{e}(\Omega)$ & 7.5 \\
Coil inductance, $L_{e}(\mathrm{H})$ & 0.002 \\
Natural angular frequency, $\omega_{c}(\mathrm{~Hz})$ & 16.3 \\
\hline
\end{tabular}

\subsection{Experimental Results and Analysis}

In order to verify the superiority of the SMC-RESO based vibration control method, a comparison experiment with the SMC-ESO method is carried out on the same plate structure. For comparison, the same frequency and amplitude of signals are applied to excite the vibration structure. When these two controllers almost achieve their optimal control effects, the parameter selections of the them are shown as follows: The parameters are chosen $c=400, k=10, \eta=2, b=4000, \omega=12$ for SMC-ESO, and $c=10, k=0, \eta=2$, $b=500, \omega=15$ for SMC-RESO.

The results of the experimental comparison for the two controllers are shown in Figure 5, where the output voltage amplitude before the control is approximately equal to $1.65 \mathrm{~V}$. When the SMC-ESO controller is adopted, the amplitude is reduced to $0.75 \mathrm{~V}$, which is reduced by $54.5 \%$. When the SMC-RESO controller is adopted, the voltage amplitude is dropped to $0.41 \mathrm{~V}$, reduced by approximately $75.2 \%$. Obviously, the vibration control performance of the all-clamped plate based on SMC-RESO method is better than SMC-ESO.
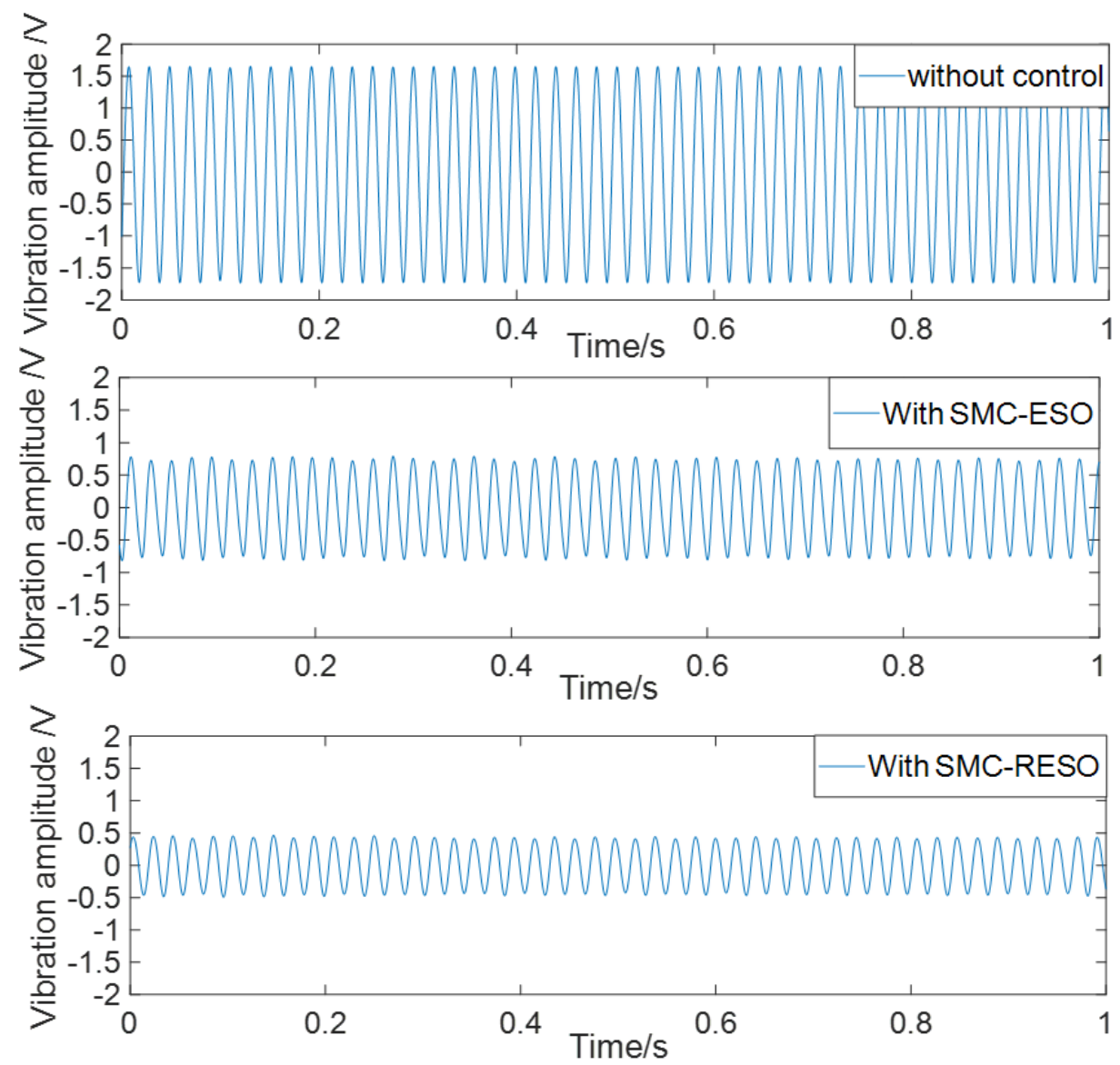

Figure 5. Time domain response. 
In addition, Figure 6 shows the FFT results of vibration amplitude. As is shown, the amplitude value of vibration has been reduced from $2.65 \mathrm{~dB}$ to $-5.67 \mathrm{~dB}$ with the SMC-ESO method, decreased by approximately $8.32 \mathrm{~dB}$. After adopting the SMC-RESO controller, the amplitude has dropped from $2.65 \mathrm{~dB}$ to $10 \mathrm{~dB}$, a total decrease of $12.65 \mathrm{~dB}$. The control voltages of the two controllers are seen in Figure 7. The control voltage of SMC-ESO controller is $4 \mathrm{~V}$, and the control voltage of SMC-RESO controller is $3.7 \mathrm{~V}$. Compared with the two control voltages, the SMC-RESO controller has better control performance with lower control voltage. Data analysis is shown in Table 2.

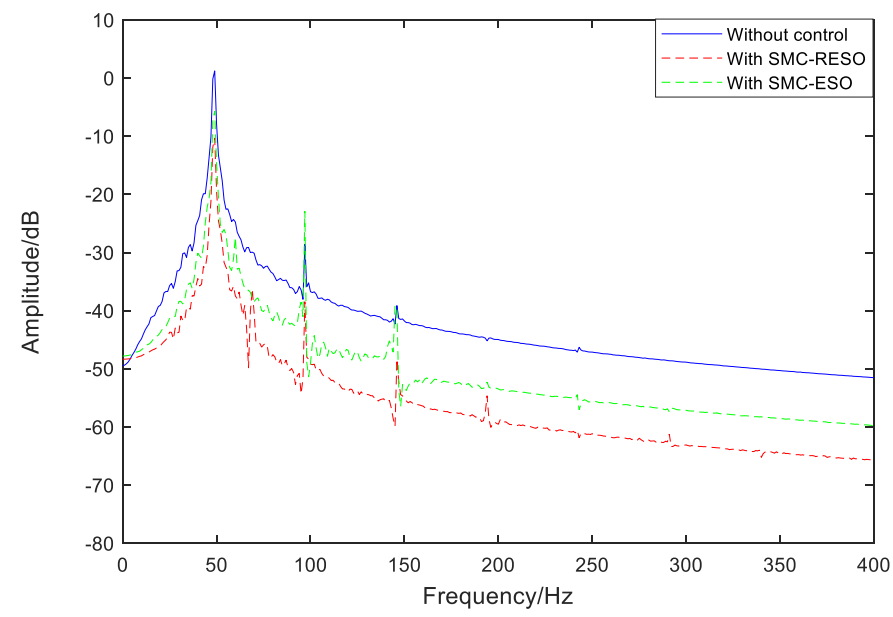

(a)

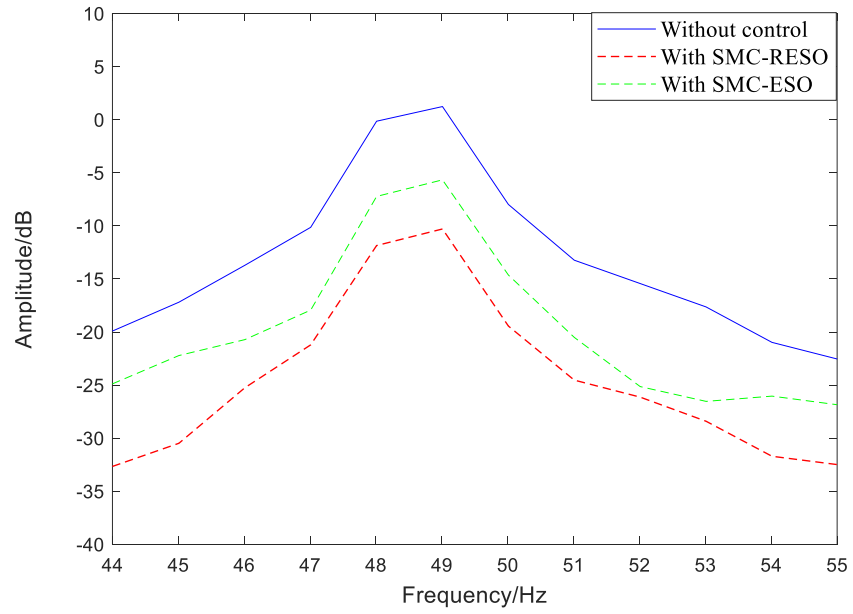

(b)

Figure 6. The FFT results of vibration amplitude: (a) frequency-response curve and (b) local frequency-response curve.
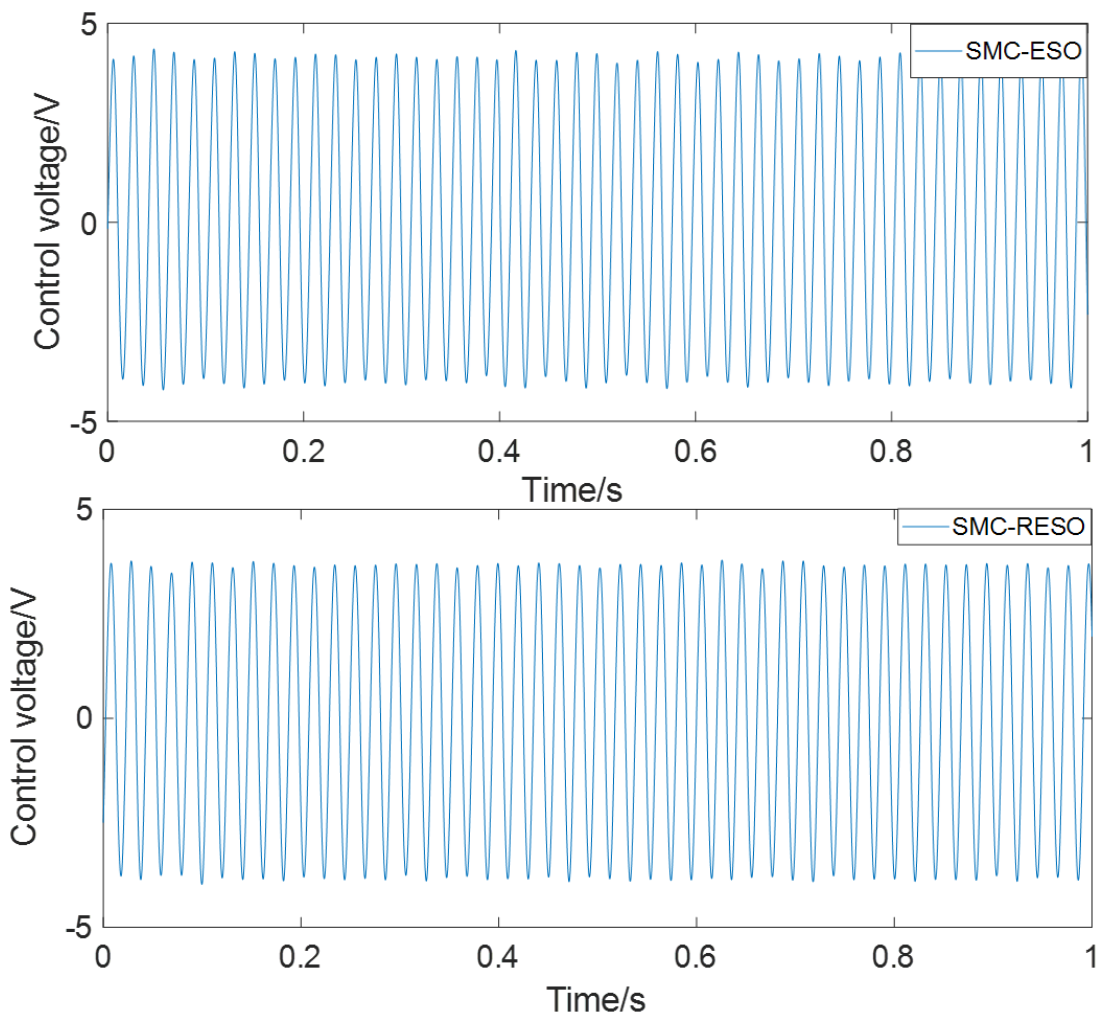

Figure 7. Experimental control voltage curves. 
Table 2. Output amplitude of different controllers.

\begin{tabular}{ccccc}
\hline Controller & Output Voltage & Degree of Inhibition & FFT Amplitude & $\begin{array}{c}\text { FFT Amplitude } \\
\text { Reduction Value }\end{array}$ \\
\hline Without control & $1.66 \mathrm{~V}$ & - & $2.65 \mathrm{~dB}$ & - \\
SMC-ESO & $0.75 \mathrm{~V}$ & $54.5 \%$ & $-5.67 \mathrm{~dB}$ & $8.32 \mathrm{~dB}$ \\
SMC-RESO & $0.41 \mathrm{~V}$ & $75.2 \%$ & $-10 \mathrm{~dB}$ & $12.65 \mathrm{~dB}$ \\
\hline
\end{tabular}

According to the table, the traditional SMC-ESO method has a good effect on internal and external disturbance. However, due to the limited computing capacity of the NI-PCIe acquisition card, time-sharing multiplexing is required. In order to further improve the performance of the system, the controller must be optimized. Therefore, the RESO method is adopted to reduce the amount of computation of the controller and use a smaller input to achieve better output performance.

\section{Conclusions}

In this paper, a compound sliding mode vibration control strategy based on a reducedorder extended state observer is proposed to solve the problems of uncertainty, high order harmonics and external disturbances in the vibration control system of the all-clamped plate. First, external disturbance and internal uncertainty are defined as a total disturbance which are estimated by RESO, and vibration suppression is achieved by compensating disturbances through feedforward part. In addition, observer errors are attenuated by SMC. As can be seen from the analysis of experimental results, the proposed SMC-RESO controller has excellent vibration performance and robustness compared with SMC-ESO.

At the same time, there are several tasks in the future. First, RESO is an observer with infinite time convergence, while disturbances is usually finite dimensional. It will be researched to suppress disturbances in finite time. Theoretically, an observer with finite time convergence can be obtained by changing the structure of RESO, which can improve the efficiency of the observer, and experimental verification will be carried out. Second, when external disturbances cannot be measured, vibration engineers can use the proposed method, because external disturbances and internal uncertainties, i.e., total disturbances, are defined by RESO as an extended state variable.

Author Contributions: Conceptualization, J.Z.; methodology, J.Z.; validation, J.Z., Z.X. and L.Z.; formal analysis, J.Z. and S.L.; data curation, J.Z.; writing-original draft preparation, J.Z.; writingreview and editing, J.Z. and S.L.; supervision, J.Z. and J.L.; funding acquisition, J.Z., S.L., Z.X., L.Z. and J.L. All authors have read and agreed to the published version of the manuscript.

Funding: This research received no external funding.

Institutional Review Board Statement: Not applicable.

Informed Consent Statement: Not applicable.

Data Availability Statement: Not applicable.

Acknowledgments: This work was supported in part by the National Natural Science Foundation of China (Grant Nos. 61903322 and 61773335), State Key Laboratory of Mechanics and Control of Mechanical Structures (Grant No. MCMS-E-0520G01), Six Talent Peaks Foundation of Jiangsu Provincial (Grant No. KTHY2018038), Ministry of Education Industry-University Cooperative Education Program (Grant No. 202102269008).

Conflicts of Interest: The authors declare no conflict of interest.

\section{References}

1. Camperi, S.; Tehrani, M.G.; Elliott, S.J. Parametric study on the optimal tuning of an inertial actuator for vibration control of a plate: Theory and experiments. J. Sound Vib. 2018, 435, 1-22. [CrossRef]

2. Kumar, Y. The Rayleigh-Ritz method for linear dynamic, static and buckling behavior of beams, shells and plates: A literature review. J. Vib. Control 2018, 24, 1205-1227. [CrossRef] 
3. Zhang, Y.; Xu, W.; Li, Z.; Yin, L. Design and dynamic analysis of low-frequency mounting system for marine thrust bearing. J. Braz. Soc. Mech. Sci. Eng. 2021, 43,1-11. [CrossRef]

4. Hayashi, Y.; Watanabe, M.; Hara, K. Active Feedback Control of a Web Flutter Using Flow Control Devices. J. Adv. Mech. Des. Syst. Manuf. 2010, 4, 269-280. [CrossRef]

5. Wang, Q.; Rajashekara, K.; Jia, Y.; Sun, J. A Real-Time Vibration Suppression Strategy in Electric Vehicles. IEEE Trans. Veh. Technol. 2017, 66, 7722-7729. [CrossRef]

6. Kim, T.; Lee, U. Vibration Analysis of Thin Plate Structures Subjected to a Moving Force Using Frequency-Domain Spectral Element Method. Shock Vib. 2018, 2018, 1-27. [CrossRef]

7. Sun, Y.; Qiang, H.; Xu, J.; Lin, G. Internet of Things-Based Online Condition Monitor and Improved Adaptive Fuzzy Control for a Medium-Low-Speed Maglev Train System. IEEE Trans. Ind. Inform. 2020, 16, 2629-2639. [CrossRef]

8. Kim, T.; Ivantysynova, M. Active Vibration Control of Swash Plate-Type Axial Piston Machines with Two-Weight Notch Least Mean Square/Filtered-x Least Mean Square (LMS/FxLMS) Filters. Energies 2017, 10, 645. [CrossRef]

9. Konieczny, J.; Sibielak, M.; Raczka, W. Active Vehicle Suspension with Anti-Roll System Based on Advanced Sliding Mode Controller. Energies 2020, 13, 5560. [CrossRef]

10. Wang, X.; Pereira, E.; Diaz, I.M.; Garcia-Palacios, J.H. Velocity feedback for controlling vertical vibrations of pedestrian-bridge crossing. Practical guidelines. Smart Struct. Syst. 2018, 22, 95-103. [CrossRef]

11. Camperi, S.; Tehrani, M.G.; Elliott, S.J. Local tuning and power requirements of a multi-input multi-output decentralised velocity feedback with inertial actuators. Mech. Syst. Signal Process. 2019, 117, 689-708. [CrossRef]

12. Diaz, C.G.; Gardonio, P. Feedback control laws for proof-mass electrodynamic actuators. Smart Mater. Struct. 2007, 16, 1766-1783 [CrossRef]

13. Zhang, L.; Li, S.; Zhu, C.; Li, J. ESO-Based Vibration Control for All-Clamped Plate Using an Electrodynamic Inertial Actuator. Int. J. Struct. Stab. Dyn. 2022, 22, 2250013. [CrossRef]

14. Zilletti, M.; Gardonio, P.; Elliott, S.J. Optimisation of a velocity feedback controller to minimise kinetic energy and maximise power dissipation. J. Sound Vib. 2014, 333, 4405-4414. [CrossRef]

15. Li, S.; Zhu, C.; Li, J.; Mao, Q. A nonlinear disturbance rejection vibration control for an all-clamped piezoelectric panel. Int. J. Appl. Electromagn. Mech. 2020, 64, 403-411. [CrossRef]

16. Sun, L.; Lin, Y.; Geng, G.; Li, Z.; Jiang, H. Research on Switching Interconnection Modes and Game Control of Interconnected Air Suspension. Energies 2019, 12, 3218. [CrossRef]

17. Takahashi, K.; Jargalsaikhan, N.; Rangarajan, S.; Hemeida, A.M.; Takahashi, H.; Senjyu, T. Output Control of Three-Axis PMSG Wind Turbine Considering Torsional Vibration Using H Infinity Control. Energies 2020, 13, 3474. [CrossRef]

18. Sun, N.; Fang, Y.; Chen, H. Tracking control for magnetic-suspension systems with online unknown mass identification. Control Eng. Pract. 2017, 58, 242-253. [CrossRef]

19. Li, S.; Zhu, C.; Mao, Q.; Su, J.; Li, J. Active disturbance rejection vibration control for an all-clamped piezoelectric plate with delay. Control Eng. Pract. 2021, 108, 104719. [CrossRef]

20. Sun, Y.; Xu, J.; Lin, G.; Sun, N. Adaptive neural network control for maglev vehicle systems with time-varying mass and external disturbance. Neural Comput. Appl. 2021, 1-12. [CrossRef]

21. Sun, N.; Wu, Y.; Chen, H.; Fang, Y. An energy-optimal solution for transportation control of cranes with double pendulum dynamics: Design and experiments. Mech. Syst. Signal Process. 2018, 102, 87-101. [CrossRef]

22. Wang, J.; Li, S.; Yang, J.; Wu, B.; Li, Q. Extended state observer-based sliding mode control for PWM-based DC-DC buck power converter systems with mismatched disturbances. IET Control Theory Appl. 2015, 9, 579-586. [CrossRef]

23. Pan, R.; Lin, G.; Shi, Z.; Zeng, Y.; Yang, X. The Application of Disturbance-Observer-Based Control in Breath Pressure Control of Aviation Electronic Oxygen Regulator. Energies 2021, 14, 5189. [CrossRef]

24. Yang, J.; Li, S.; Yu, X. Sliding-Mode Control for Systems with Mismatched Uncertainties via a Disturbance Observer. IEEE Trans. Ind. Electron. 2013, 60, 160-169. [CrossRef]

25. Zhang, J.; Liu, X.; Xia, Y.; Zuo, Z.; Wang, Y. Disturbance Observer-Based Integral Sliding-Mode Control for Systems with Mismatched Disturbances. IEEE Trans. Ind. Electron. 2016, 63, 7040-7048. [CrossRef]

26. Han, J. From PID to Active Disturbance Rejection Control. IEEE Trans. Ind. Electron. 2009, 56, 900-906. [CrossRef]

27. Wang, G.; Liu, R.; Zhao, N.; Ding, D.; Xu, D. Enhanced Linear ADRC Strategy for HF Pulse Voltage Signal Injection-Based Sensorless IPMSM Drives. IEEE Trans. Power Electron. 2019, 34, 514-525. [CrossRef]

28. Xue, W.; Bai, W.; Yang, S.; Song, K.; Huang, Y.; Xie, H. ADRC with Adaptive Extended State Observer and its Application to Air-Fuel Ratio Control in Gasoline Engines. IEEE Trans. Ind. Electron. 2015, 62, 5847-5857. [CrossRef]

29. Ren, C.; Li, X.; Yang, X.; Ma, S. Extended State Observer-Based Sliding Mode Control of an Omnidirectional Mobile Robot With Friction Compensation. IEEE Trans. Ind. Electron. 2019, 66, 9480-9489. [CrossRef]

30. Huang, Y.; Xue, W. Active disturbance rejection control: Methodology and theoretical analysis. ISA Trans. 2014, 53, 963-976. [CrossRef]

31. Wa, J.; Rong, J.; Li, Y. Reduced-order extended state observer based event-triggered sliding mode control for DC-DC buck converter system With parameter perturbation. Asian J. Control 2021, 23, 1591-1601. [CrossRef]

32. Zhao, Z.-L.; Guo, B.-Z. A nonlinear extended state observer based on fractional power functions. Automatica 2017, 81, 286-296. [CrossRef] 